\title{
Effects of Bolt Distance on Flexural Behavior of Bolt-Laminated Bamboo Beam
}

\author{
Gusti Made Oka, Andreas Triwiyono, and Suprapto Siswosukartoand Ali Awaludin
}

\begin{abstract}
Bolt-laminated bamboo beam was utilized as an alternative to replace wood and it was used as structural and non-structural construction material. Bamboo material then has become the most popular non-wood material in construction field. Nowadays, bamboo material is not optimally utilized yet. Many studies showed the advantages of bamboo to be compared to the other materials. The diameter of Gigantochloaatroviolacea bamboo used in this study is ranged from 70 to $90 \mathrm{~mm}$. The diameter of bolt is $12.7 \mathrm{~mm}$. The improvement of strength and bending stiffness of beam can be conducted by arranging the full-culm bamboo with bolt as the shear connector. Variations of bolt distance in this study were $125 \mathrm{~mm}, 250 \mathrm{~mm}$ and $500 \mathrm{~mm}$. The final product of the bamboo jointed segment is bolt-laminated bamboo beam. Setup test for bolt-laminated bamboo bemuses four point bending method. The strength and bending stiffness of boltlaminated bamboo beam has increased as the bolt distance decreased.The shear connector distance that are greater than $500 \mathrm{~mm}$ has no significant affect to the strength and bending stiffness of the beam. Therefore, the distance of bolts is suggested to be less than $500 \mathrm{~mm}$.
\end{abstract}

Index Terms-Bamboo beam, bolt distance, strength, stiffness.

\section{INTRODUCTION}

The need of wood in construction sharply increases. Therefore, it is difficult to obtain wood beams with large size and good quality. This problem can be solved by seeking an alternative material to wood substitution. Bamboo has immense opportunities to be used as wood alternative replacement material because it has rapid growth, can be harvested at age of 3-5 years, and has high mechanical properties [1].

Factors that affect the mechanical properties of bamboo are species of bamboo, age of bamboo, condition, moisture content, form and size of the specimens, node or internodes, position along the culm (bottom, middle and top) and testing speed [2].

Currently, the Gigantochloa atroviolaceabamboo has been used as a construction material in Yogyakarta, Indonesia, but the influence of mechanical properties, i.e. the species and age, height position, node or internode of the culm, has not been studied in detail [3]. In addition to the high ratio of strength to weight, bamboo also has relatively low cost and fast growth rate. Therefore, it is importat to have the mechanical and physical characteristic of all bamboo species, in order to have a more reliable

Manuscript received May 8, 2014; revised August 4, 2014.

The authors are with the Department of Civil Engineering and Environment, Gadjah Mada University, Indonesia (e-mail: oka7166@yahoo.com). understanding of their behavior for a better structural design and performance [4].

Regarding the structural design of bamboo building, when the span of structure is relatively long, the more strength and bending stiffness of bamboo materials is needed. The strength and bending stiffness of bamboo material can be improved by combining them vertically and jointed with bolt shear connector. Bolt-laminated bamboo beam is a bamboo structural component, which is arranged horizontally with bolt as its shear connector without void filled material. The horizontal friction between bamboos can be prevented using shear connector, i.e. bolts, with certain distance to achieve the required strength of full-bamboo beam layers. The strength and bending stiffness of boltlaminated bamboo beam are affected by several factors such as number of bamboo used for the beam, specific gravity, bamboo diameter, bolt diameter and distance between bolts.

Some disadvantages of bamboo are 1) it is a Nonhomogeneous material, 2) it has non-prismatic sectional form, 3) the straightness of the culms is not similar, 4) the culm has nodes and it has hollow inner section. Application of bamboo as building material is needed to understand its mechanical properties in order to be optimally utilized. Therefore, there is no surplus either shortage of bamboo [4]. The objective of these researches to determine the influence of bolt distance on strength and bending stiffness of boltlaminated bamboo beam.

\section{MATERIALS AND METHOD}

Bamboo type that was used for bolt-laminated bamboo beam in this study was Gigantochloaatroviolacea (black bamboo). The culms were taken from the same culm. The bamboo culm was cut at $50 \mathrm{~cm}$ above the ground. Each culm was cut for 3.5 mof length. Specimens of moisture content were evaluated using samples in the form of split bamboo [5] and tested at 15\% moisture content [6]. The form of specimens of moisture content can be prism lookalike, approximately $25 \mathrm{~mm}$ of width, $25 \mathrm{~mm}$ of height and the wall thickness of bamboo. In this study, the bolt diameter was $12.7 \mathrm{~mm}$ and bamboo diameter was 70-90 $\mathrm{mm}$. This bamboo species has been widely used for many types of engineering construction such as frame, truss and roof system.

Bolt-laminated bamboo beam material was made in two groups, i.e. Layers Double Beam (LDB) and Layers Triple Beam (LTB) as shown in Fig. 1 and Fig. 2. Each group of LDB and LTB beam was made in five models. The first model was the beams with combination of adhesive and bolt with the distance of $125 \mathrm{~mm}$. The second, third and fourth model used bolt with the distance of $125 \mathrm{~mm}, 250 \mathrm{~mm}$ and 
$500 \mathrm{~mm}$. The fifth model is beam without shear connector. The first beam model was labeled as LDB.A.125. And LTB. A. 125. The second beam model is labeled as LDB.125. And LTB. 125. The third beam model is labeled as LDB.250. and LTB.250. The fourth beam model is labeled as LDB.500 and LTB.500. The last beam model is labeled as LDB-NS and LTB-NS. Bamboo jointed segment was shaped from full-bamboo culms with bolt as the shear connector without void filler material to make bolt-laminated bamboo beam.

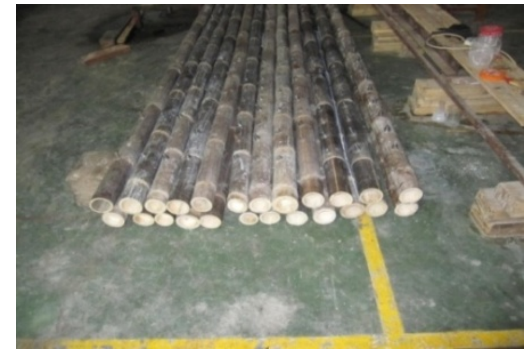

Fig. 1. Specimens of LDB beam.

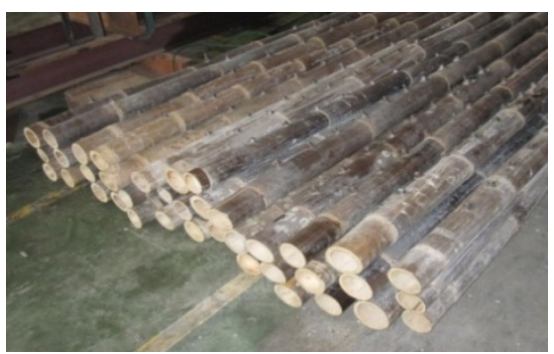

Fig. 2. Specimens of LTB beam.

The curvature of beam can be determined with Finite Difference Method. Curvature line can be determined by used of Taylor series if the points that traversed a function are known [7]. Finite Difference Method can be applied to determine the curvature of beam using 3 LVDT in Fig. 3.

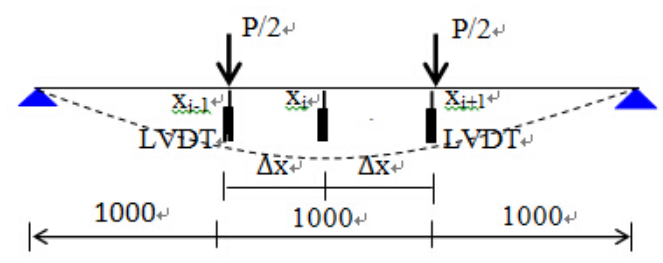

Fig. 3. The curvature of beam.

$$
\begin{aligned}
& f\left(x_{i+1}\right)= \\
& f\left(x_{i}\right)+f^{\prime}\left(x_{i}\right) \frac{\Delta_{x}}{2 !}+f^{\prime \prime}\left(x_{i}\right) \frac{(\Delta x)^{2}}{2 !}+f^{\prime \prime \prime}\left(x_{i}\right) \frac{(\Delta x)^{3}}{3 !}+ \\
& f^{\prime \prime \prime \prime}\left(x_{i}\right) \frac{(\Delta x)^{4}}{4 !} \\
& f\left(x_{i-1}\right)= \\
& f\left(x_{i}\right)-f^{\prime}\left(x_{i}\right) \frac{\Delta_{x}}{2 !}+f^{\prime \prime}\left(x_{i}\right) \frac{(\Delta x)^{2}}{2 !}-f^{\prime \prime \prime}\left(x_{i}\right) \frac{(\Delta x)^{3}}{3 !}+ \\
& f^{\prime \prime \prime \prime}\left(x_{i}\right) \frac{(\Delta x)^{4}}{4 !}
\end{aligned}
$$

Equation (1) and equation (2) is added to obtain:

$$
k=f^{\prime \prime}\left(x_{i}\right)=\frac{f\left(x_{i+1}\right)-2 f\left(x_{i}\right)+f\left(x_{i-1}\right)}{(\Delta x)^{2}}
$$

Equation (3) is the magnitude of function curvature, and then this equation is presented to determine the magnitude of beam curvature.

Stiffness is the capacity of beam to restrain the change of its form due to an external load. Beam bending stiffness is calculated using moment and beam curvature, as it is shown in equation (4).

$$
E I=\frac{M}{K}
$$

Dimension of LDB beam specimen is $3000 \mathrm{~mm}$ of length and 2 bamboo jointed segments, as shown in Fig. 1, while dimension of the LTB beam specimen is $3000 \mathrm{~mm}$ of length and 3 bamboo jointed segments, as shown in Fig. 2. The equipment was used in this study, i.e. hydraulic jack, load cell, LVDT and data logger. Setup test used the configuration of four bending points of LDB and LTB beam in Fig. 4 and Fig. 5. The test of beam is performed by monotonic loading method. Load is performed by load cell using a hydraulic jack. Deflection is conducted using 3 LVDTs on center span and at the load point. The measurement of displacement was conducted step by step, because the capacity of LVDT was limited as $50 \mathrm{~mm}$ and displacement of bolt-laminated bamboo beam was larger. Base on of all mechanical properties at bamboo modulus elasticity is small.

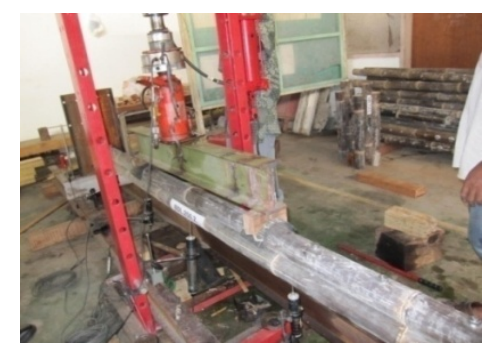

Fig. 4. Setup test of LDB beams.

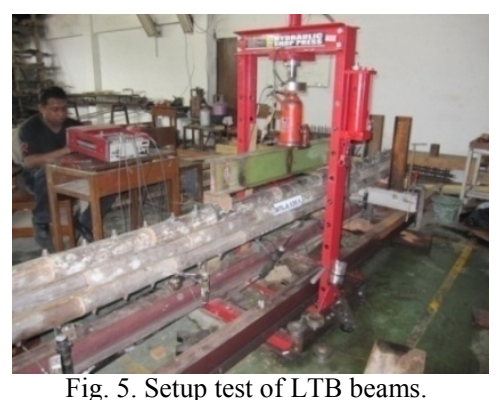

\section{RESULTS AND DISCUSSION}

There are various results of moisture content teston the specimens, from $12.95 \%$ to $16.16 \%$ with an average value of $14.59 \%$ from 24 bamboo specimens. Base on of requirement BSN standard as building material is moisture content $15 \%$ [5].

Fig. 6 shows the relationship between load and deflection of all LDB beam specimens, while Fig. 7 shows the relationship between load and deflection of all LTB beam specimens. Base on of test result on LDB and LTB beam was obtained of maximum beam strength at first model between adhesive and bolt. The strength and bending stiffness of bolt-laminated bamboo beam has increased as the bolt distance decreased. The displacement of boltlaminated bam bu beam is relatively large, because bamboos have got of modulus elasticity that relatively small between 
5000-30000 MPa. If in building structure is needed of material capacity and span length that larger, so that beam is made as bolt-laminated bamboo beam. Beside of shear connector distance is affected of strength and bending stiffness that is bamboo uniqueness. The strength of LDB and LTB beam is showed to increase as bolt distance decreased. The unique behavior of bamboo is larger diameter, so the wall thickness is not necessarily of large. All mechanical properties are varied from bottom to top and bamboo is non-prismatic material.

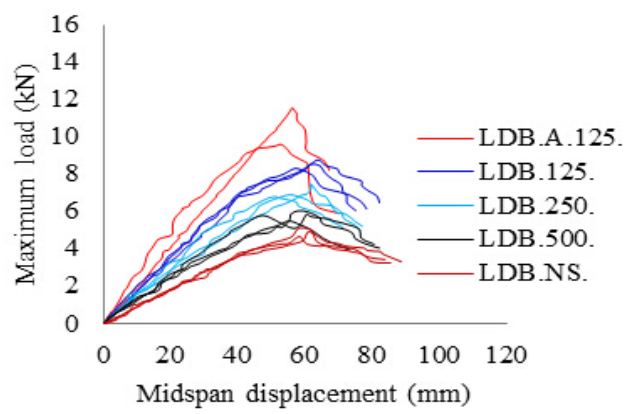

Fig. 6. Load and deflection relationship of LDB beams.

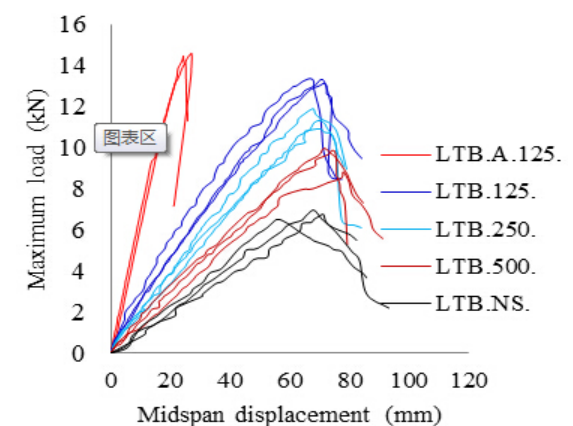

Fig. 7. Load and deflection relationship of LTB beams.

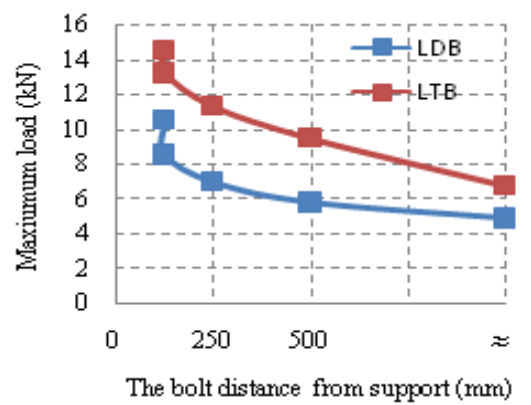

Fig. 8. Comparison of LDB and LTB beam strength.

This research uses28 beam specimens, Layer Double Beam (LDB) has 14 specimens and Layer Triple Beam (LTB) has 14 specimens. Test resultof Layers Double Beam (LDB) is shown in Table I, for strength and bending stiffness of beam, while strength and bending stiffness of Layer Triple Beam (LTB) is shown in Table II. The maximum strength of LDB beam specimens that were evaluated is various, with average value of $11,05 \mathrm{kN}, 8.55$ $\mathrm{kN}, 6.90 \mathrm{kN}, 6.03 \mathrm{kN}$ and 4,50 kN, while the maximum strength of LTB beam has average value of $14,54 \mathrm{kN}, 13.24$ $\mathrm{kN}, 11.38 \mathrm{kN}, 10,07 \mathrm{kN}$ and 7,70 kN. The proportional bendingstiffness of LDB beam specimens is various, with average value of $0.600 \times 10^{11} \mathrm{Nmm}^{2}, 0.489 \times 10^{11} \mathrm{Nmm}^{2}$, $0.447 \times 10^{11} \mathrm{Nmm}^{2}, \quad 0.388 \times 10^{11} \mathrm{Nmm}^{2}$ and $0.274 \times 10^{11}$ $\mathrm{Nmm}^{2}$, while the proportional stiffness of LTB beam has average value of $1.482 \times 10^{11} \mathrm{Nmm}^{2}, 1.239 \times 10^{11} \mathrm{Nmm}^{2}$ $0.999 \times 10^{11} \mathrm{Nmm}^{2}, \quad 0.874 \times 10^{11} \mathrm{Nmm}^{2}$ and $0.773 \times 10^{11}$ $\mathrm{Nmm}^{2}$. The strength and bending stiffness of LDB and LTB beam increase as the bolt distance decreases. Comparison of LDB and LTB beam strengths is shown in Fig. 8, while comparison of LDB and LTB beam bending stiffness is shown in Fig. 9.

Factors that affect strength and bending stiffness of boltlaminated bamboo beam are non-homogeneous bamboo, difference culms straightness, culms contained node and has void inner cross-section. Height position of nonhomogeneous bamboo is various with different mechanical properties. The different culm straightness of the beam causes gapon the beam strength decreases. Node was affected by mechanical properties of bamboo as boltlaminated material. The bamboo is easily split due to the hollow inner section. Beside of bamboo uniqueness and mechanical properties are affected of strength and bending stiffness, i.e. species and age of bamboo, topography, node and inter node, high position (bottom, middle and top), moisture content, shape and size of bolt-laminated bamboo beam. The beam geometry shape is affected of strength and bending stiffness, i.e. specific gravity, number of bamboo component, member jointed shape, bamboo diameters, bamboo wall thickness, bolt diameters and distance as beam parameters.

TABLE I: STRENGTH AND STIFFNESS OF LDB BEAM

\begin{tabular}{lcc}
\hline \hline Specimens & Load & Bending Stiffness \\
\cline { 2 - 3 } & $\begin{array}{c}P_{\max } \\
(\mathrm{kN})\end{array}$ & $\begin{array}{c}E I_{\text {pro }} \\
\left(10^{11} \mathrm{Nmm}^{2}\right)\end{array}$ \\
\hline \hline LDB.A.125.1. & 11.50 & 0.648 \\
LDB.A.125.2. & 10.60 & 0.551 \\
LDB.125.1. & 8.32 & 0.482 \\
LDB.125.2. & 8.77 & 0.495 \\
LDB.125.3. & 8.55 & 0.491 \\
LDB.250.1. & 7.27 & 0.464 \\
LDB.250.2. & 6.97 & 0.444 \\
LDB.250.3. & 6.45 & 0.436 \\
LDB.500.1. & 5.90 & 0.399 \\
LDB.500.2. & 6.15 & 0.365 \\
LDB.500.3. & 6.05 & 0.399 \\
LDB.NS.1. & 4.67 & 0.294 \\
LDB.NS.2. & 4.35 & 0.274 \\
LDB.NS.3. & 4.47 & 0.256 \\
\hline \hline
\end{tabular}

TABLE II: STRENGTH AND STIFFNESS OF LTB BEAM

\begin{tabular}{lcc}
\hline \hline Specimens & Load & Bending Stiffness \\
\cline { 2 - 3 } & $\begin{array}{c}P_{\max } \\
(\mathrm{kN})\end{array}$ & $\begin{array}{c}E I_{\text {pro }} \\
\left(10^{11} \mathrm{Nmm}^{2}\right)\end{array}$ \\
\hline LTB.A.125.1. & 14.47 & 1.446 \\
LTB.A.125.2. & 14.60 & 1.518 \\
LTB.125.1. & 13.27 & 1.167 \\
LTB.125.2. & 13.57 & 1.334 \\
LTB.125.3. & 12.87 & 1.217 \\
LTB.250.1. & 11.32 & 0.951 \\
LTB.250.2. & 11.90 & 1.064 \\
LTB.250.3. & 10.92 & 0,981 \\
LTB.500.1. & 9.97 & 0.881 \\
LTB.500.2. & 9.82 & 0.854 \\
LTB.500.3. & 10.42 & 0.887 \\
LTB.NS.1. & 7.41 & 0.802 \\
LTB.NS.2. & 7.72 & 0.784 \\
LTB.NS.3. & 7.96 & 0.734 \\
\hline \hline
\end{tabular}




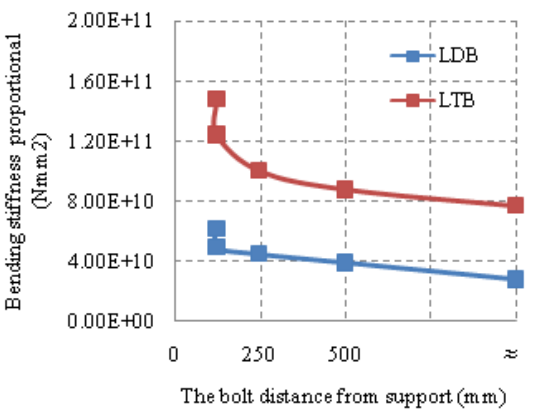

Fig. 9. Comparison of LDB and LTB beam bendingstiffness.

Base on of Tabel I and Table II present a summary of the load at time of the ultimate load that is LDB.A.125 and LTB.A.125. The average results of ultimate strength were showed $11.5 \mathrm{kN}$ and $14.47 \mathrm{kN}$ for LDB.A.125 and LTB.A.125 beam respectively. In general for all the materials ultimate load test results of the test have trend increased as bolt distance decreased. In addation adhesive (LDB.A.125 and LTB.A.125), beams bending strength increased. It is the result of a combination between adhesive and bolt of commulatively increasing the bending strength of the LDB.125 (LTB.125), LDB.250 (LTB.250), LDB.500 (LTB.500), LDB. NS (LTB.NS) at ultimate load. Base on Fig. 8 of beam ultimate strength difference is small relatively, so that the distance of bolts is suggested to be less than 500 mm. Base on Fig. 6 and Fig. 7 can be concluded that beam is adhesive addition give advantages can be increased of beam strength and bending stiffness. Comparison ratio between LDB.A.125 beam strength with LDB.125, LDB 250, LDB.500 and LDB.NSbeam strength is 0.77, 0.62, 0.55, 0.41 respectively, while comparison ratio between LTB.A.125 beam strength with LTB.125, LTB.250, LTB.500, LTB.NS beam strength is $0.91,0.78,0.69,0.53$ respectively. Base on of comparison ratio between LDB.A.125 beam strength with LDB.125, LDB.250, LDB.500, LDB.NS is showed to decrease as bolt distance increased, while comparison ratio between beam strength with LDB.125, LDB.250, LDB.500, LDB.NS is showed to increase of bolt distance increased. Increasing of beam strength from LDB beam to LTB beam is $131,58 \%$, $154.85 \%, 164.93 \%, 167.00 \%, 171.11 \%$ respectively.

Base on of Table I and Table II show a summary of proportional bending stiffness of LDB.A.125 and LTB.125 beam is conducted of larger bending stiffness value. It is the result of a combination between adhesive and bolt of cumulatively increasing the bending stiffness from beam model as such the LDB.125 (LTB.125), LDB.250 (LTB.250), LDB.500 (LTB.500), LDB.NS (LTB.NS) at proportional bending stiffness. In general Fig. 9 of beam bending stiffness the difference is small relatively, so that the bolt distance is suggested to be less than $500 \mathrm{~mm}$. The beam of LDB.NS and LTB.NS is intended as compored of LDB and LTB beam. Comparison ratio between LDB.A.125 beam strength with LDB.125, LDB 250, LDB.500 and LDB.NS beam strength is $0.82,0.75,0.63,0.45$ respectively, while comparison ratio between LTB.A.125 beam strength with LTB.125, LTB.250, LTB.500, LTB.NS beam strength is $0.84,0.767,0.59,0.52$ respectively. Base on of comparison ratio between LDB.A.125 beam bending stiffness with LDB.125, LDB.250, LDB.500, LDB.NS is showed to decrease as bolt distance increased, while comparison ratio between beam bending stiffness with LDB.125, LDB.250, LDB.500, LDB.NS is showed to increase of bolt distance increased.Increasing of beam bending stiffness fromLDB beam to LTB beam is $246.67 \%$, $253.06 \%, 222.22 \%, 228.95 \%, 285.18 \%$ respectively.

In general, the pattern of failure model of Layer Double Beam (LDB) and Layer Triple Beam(LTB) is shown in Fig. 10 and Fig. 11. The flexural failure model began to occur when the force stress exceeds the compression strength at upper part of bamboo material. The addition of the adhesive dan bolt can be increased of beam strength and bending stiffness. The biggest strength and stiffness beams is obtained on the beam combination of adhesive and distance a bolt at $125 \mathrm{~mm}$.Majority of failure modeloccurs on the upper beam fiber during form split, while the bolt has not experienced a form change(elasticity behavior) showed in Fig. 12. The failure Model of LDB and LTB beam is splitted on upper part and this isbeam compression part.This difference can be showed from compression and tensile strength value diferrenceis $54.68 \mathrm{MPa}$ and $187.34 \mathrm{MPa}$ respectively [4]. The solution of splitted bamboo is made load support coated with rubber.The support shape of circumference is avoided to occur oftwisting at beam test.

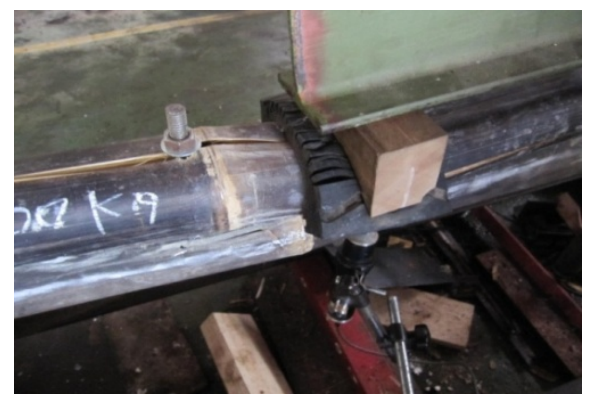

Fig. 10. Failure model of LDB beam.

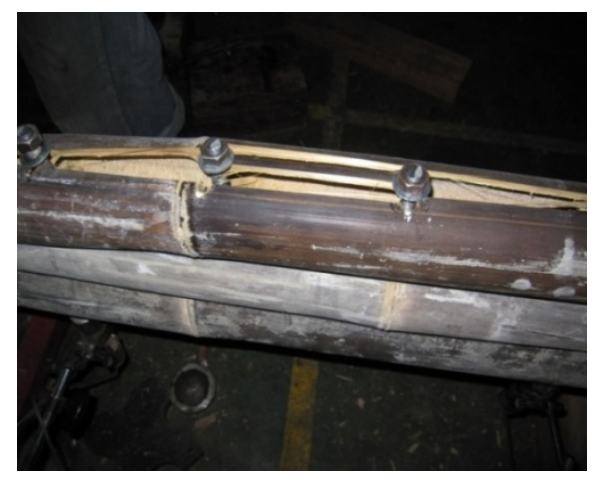

Fig. 11. Failure model of LTB beam.

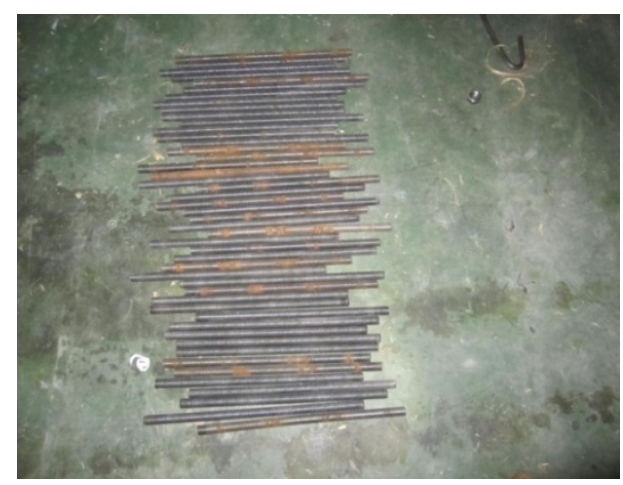

Fig. 12. Failuremodel of bolt. 


\section{CONCLUSIONS}

A study on flexural behavior of bolt-laminated bamboo beam using LBD and LTB beam test configuration has been conducted. The average strength of LDB beam are $11.05 \mathrm{kN}$, $8.55 \mathrm{kN}, 6,90 \mathrm{kN}, 6.03 \mathrm{kN}$ and $4.50 \mathrm{kN}$, while the stiffness proportional of LDB beam are $0.600 \times 10^{11} \mathrm{Nmm}^{2}$, $0.489 \times 10^{11} \mathrm{Nmm}^{2}, 0.447 \times 10^{11} \mathrm{Nmm}^{2}, 0.388 \times 10^{11} \mathrm{Nmm}^{2}$ and $0.274 \times 10^{11} \mathrm{Nmm}^{2}$. The average strengths of LTB beam are $14.54 \mathrm{kN}, 13.24 \mathrm{kN}, 11.38 \mathrm{kN}, 10,07 \mathrm{kN}$ and $7.70 \mathrm{kN}$, while the stiffness proportional of LTB beam are $1.482 \times 10^{11}$ $\mathrm{Nmm}^{2}, 1.239 \times 10^{11} \mathrm{Nmm}^{2}, 0.999 \times 10^{11} \mathrm{Nmm}^{2}, 0.874 \times 10^{11}$ $\mathrm{Nmm}^{2}$ and $0.773 \times 10^{11} \mathrm{Nmm}^{2}$. This study shows that the bolt distance is a combination of adhesive and a $125 \mathrm{~mm}, 125$ $\mathrm{mm}, \quad 250 \mathrm{~mm}, \quad 500 \mathrm{~mm}$ and non-shear connector.Comparison ratio between LDB.A.125 beam strength with LDB.125, LDB 250, LDB.500 and LDB. NSbeam strength is $0.82,0.75,0.63,0.45$ respectively, while comparison ratio between LTB.A.125 beam strength with LTB.125, LTB.250, LTB.500, LTB.NS beam strength is $0.84,0.767,0.59,0.52$ respectively. Comparison ratio between LDB.A.125 beam strength with LDB.125, LDB 250, LDB.500 and LDB. NSbeam strength is 0.82, 0.75, $0.63,0.45$ respectively, while comparison ratio between LTB.A.125 beam strength with LTB.125, LTB.250, LTB.500, LTB.NS beam strength is $0.84,0.767,0.59,0.52$ respectively.

\section{ACKNOWLEDGEMENTS}

The Author would like to send his gratitude the Promoters for supporting his Doctoral program. He also would like to thank the staff of the Structure Engineering Laboratory and staff of Graduate Program of Department of Civil Engineering, Gadjah Mada University, for the assistance.

\section{REFERENCES}

[1] A. S. Nordahlia, U. M. K. Anwar, H. Hamdan, M.A. Latif, and S. M. A. Mahanim, "Anatomical, physical and strength properties of Shizostachyumbrachyladum (Buluhlemang)," Journal Bamboo and Rattan, vol.10, pp. 111-1222, 2011.

[2] J. J. A. Janssen, "Bamboo in building structures," thesis the Eidhoven University of Technology, 1981.

[3] D. J. F. Correal and C. J. Arbelaez, "Influence of age and height position on colombian guaduaangustifolia bamboo mechanical properties," Maderas, Ciencia y tecnologia,. vol. 12, no. 2, pp. 105 113,2010

[4] Morisco, Bamboo of Technology, Graduate of Engineering School, Gadjah Mada University, pp. 11-30, 2005.

[5] Determination of Physical and Mechanical Properties Bamboo, International Standard, 2004.

[6] Procedure of design wood construction, SNI, 2002, BSN, Indonesia

[7] B. Triatmodjo, Numerical Method and Fitted with a Computer Program, Second Edition, Beta Offset, pp. 7-19, 2010.

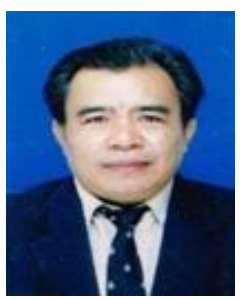

Gusti Made Oka is a doctoral student on Departement of Civil Engineering, Gadjah Mada University, Yogyakarta, Indonesia, concerning in structure. He was born in Blahkiuh, Bali, Indonesia on December 30, 1966. He graduated with a bachelor diploma engineer (DIII).

$\mathrm{He}$ received his degree from Tadulako University, Palu, Central Sulawesi, Indonesia, in 1987. And he obtained a bachelor of engineering (ST) from Hasanuddin University, Makassar, South Sulawesi, Indonesia, in 1994. He graduated with master of engineering (MT) degree in Department of Civil Engineering and Environment, Gadjah Mada University, Yogyakarta, Indonesia, in 2004.

$\mathrm{He}$ is a lecturer at the Department of Civil Engineering, Tadulako University, and Central Sulawesi, Indonesia. He teaches such as timber structure, mechanics of materials, steel of structure, statically. He current research interests include bamboo material as application of fullbamboo as a beam, column, truss and splitting bamboo in the form of laminated as panel, beam and column laminated.

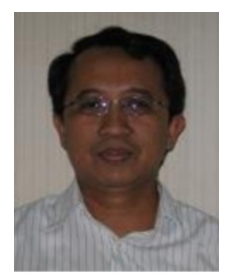

Andreas Triwiyono is an assistant professor concerning in the field of reinforced concrete structure, evaluation and rehabilitation of bridge management system. He was born in Sragen, Central Java, Indonesia in 1962.

He graduated with bachelor of civil engineering, at the Gadjah Mada University, Yogyakarta, Indonesia, in 1986. He obtained a doctor in genieur, from Civil Engineering Department, Universitaet Gesainthochochschule Kassel, Germany, in 1996. He is the head of the Structural Engineering Laboratory, Department of Civil and Environment, Gadjah Mada University, Yogyakarta, Indonesia, as a lecturer. His major interest is design of reinforced concrete structure. He is also involved in the study of evaluation and rehabilitation of reinforced concrete structure and bridge management system. He was also active in the organization of civil engineering. He is currently a member of the Indonesia Soc Engineers as Society of Civil and Structural Engineers a and the Indonesia Society of Precast and Precast Engineers, National, Indonesia. Currently he teaches analysis of determinate structure, analysis of stresses, strains and deformations, design of reinforced concrete structure, precast and progressed concrete structure, bridge structure analysis, constitutive model of materials. His current research interests include reinforced concrete structure, evaluation and rehabilitation of reinforced structure and bridge management system.

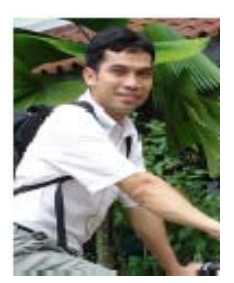

Ali Awaludin is an assistant professor in the field of timber engineering and bamboo structures. He was born in Bandung, West Java, Indonesia, November 17, 1977. In 1999 he completed University of Gadjah Mada, Indonesia.

He obtained a master of civil engineering, Chulalongkorn University, Thailand in 2005. And he obtained a doctor degree in engineering from the University of Hokkaido, Japan, 2008 and post doctoral degree in engineering from Hokkaido University, Japan, 2010. $\mathrm{He}$ is the head of the Timber and Bamboo Engineering Laboratory, Department of Civil Engineering and Environment, Gadjah Mada University, Yogyakarta, Indonesia, as a lecturer. His current research interests include timber engineering, sustainable building materials and environmental vibration. Currently he teaches of timber and bamboo engineering, structural analysis, timber structure and technology, earthquake-resistance timber structure, steel structure, mechanics of continua.

$\mathrm{He}$ is a member of some professional organizations such as Japan Wood Research Society, International, 2005 and Indonesian Wood or Research Society, National, in 2010.

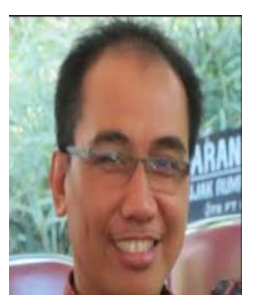

Suprapto Siswosukarto is an assistant professor on the use of polystyrene and Styrofoam of concrete technology. He was born in Bantul, Yogyakarta Special Region, Java, Indonesia, April 7, 1965. He graduated with a bachelor of engineering degree in civil engineering department, Gadjah Mada University, Yogyakarta.

He obtained a doctor degree in engineering (Ph.D) from City University, UK, in 2005. He is the head of program graduated of master and doctoral, Department Civil and Environment, Gadjah Mada University, Yogyakarta, Indonesia, and he is also a lecturer. Currently he teaches analysis of determinate structure, analysis of indeterminate structure, design of reinforced concrete structure, design of steel structure. He is currently a member of the Indonesian Structural Engineers Association (HAKI), National, Indonesia. His current research interests include experimental study on the microstructure and strength concrete using polystyrene and Styrofoam as technology innovation. 